\title{
Changing Learning Environments for a Changing Workplace
}

New Zealand Journal of Teachers' Work, Volume 12, Issue 1, 4-5, 2015

\author{
NIKKI URLICH \\ Campbells Bay School
}

Imagine a daily workday in the same ten metre squared area with the same 30 young people of the same age. One will leave this space twice during the day, at the same time as everyone else-regardless of whether one is engaged in fruitful work and thought at the time. The sound of a bell punctuates this coming and going. All employees will break for twenty minutes, to return (if at all possible) to the thinking left behind before the break. If there is time for collaborative work with teammates, that too is carried out by all at the same time.

The image of the factory floor, of workers performing the same job at the same time to mass produce widgets for society, their movements regulated by bells, and disciplined regimentation, is an image of the past. In that past time, we needed schools to educate people, so they were 'work' ready for this kind of employment.

That meant students entering a school year by age cohort, working in one space for the entire day, or a dedicated space for each period in high school. They would learn the same material at the same time, have breaks at the same time, and usually they were told to be quiet in-between breaks. When it was time to read, they read, and when time to do maths, they 'did' maths. The same cycle would be repeated each year.

While this scenario still exists in some workplaces, it is becoming much less common. Business workplaces have changed significantly since the industrial age, yet our classrooms seem to take longer to change. Until now, that is, as seen by the recent shift toward modern learning practices and new modern learning environments, also known as innovative learning environments or flexible learning spaces.

These new learning spaces are a policy priority for the New Zealand Ministry of Education, to enable learning and teaching that will foster in young people the ability to operate and succeed in $21^{\text {st }}$ century society. Education is about preparing students for their future, and should not be preparing students for an irrelevant past.

To succeed in the $21^{\text {st }}$ century, students should learn to be self-directed, self-motivated, and able to learn with and from peers. They should be able to collaborate and communicate, and be able to use relevant and appropriate tools efficiently and successfully to find, acquire and use knowledge. Therefore, teachers and environments that facilitate this type of learning are also required.

To achieve these objectives, students need an environment with multiple learning settings and a variety of tools, so they can extend their learning and understanding when they are ready, and to call on their teachers' help when 
they need to. The workplace of the $21^{\text {st }}$ century has less need for students who are made to sit in a class and learn only what the teacher deems sufficiently important.

Recently, in what appears to be one-sided journalism, negative criticism has been aimed at these modern learning environments. Claims include that this change to school environments is a move to big open barns, and is a repeat of the failed open plan learning of the 1970's. It seems the journalists have not visited schools whose student achievement, teacher practice, and student engagement has benefitted by the new environments.

The important point being missed though is that it is not the spaces that are important, but the teaching and learning practice that is. Poor learning will happen in a fantastic classroom with all the modern bells and whistles if the teaching is incompetent. Likewise, a fantastic teacher under a tree will produce results.

The success of these new spaces is therefore dependent on teachers' teaching practice. Therefore, these new spaces will not be successful unless schools support their teachers to teach successfully in the modern environments, which, in turn, are needed for students to learn to be successful in $21^{\text {st }}$ century workplaces.

These new learning environments are not about, as suggested in the media, teachers taking a back seat, or being absent from students' learning. Instead, teachers in these environments are now facilitating the learning of the students in these new spaces.

Judgements should be based on current research behind these environments, and on considering the needs of today's children. Above all, evidence of whether these environments are effective should support judgements, rather than feelings, opinions and concerns.

The opinions expressed are those of the paper author(s) and not the New Zealand Journal of Teachers' Work. Copyright is held by individual authors but offprints in the published format only may be distributed freely by individuals provided that the source is fully acknowledged. [ISSN-1176-6662] 